\title{
Small cell carcinoma lung presented as both Pancoast and superior vena cava syndrome: a case report Rajdeep Basu, Sukalpa Chaudhuri, Soumitra Ghosh
}

Department of Internal Medicine, Institute of Post-Graduate Medical Education and Research and Seth Sukhlal Karnani Memorial Hospital, Kolkata, West Bengal, India

Correspondence to Rajdeep Basu, MBBS, 115/2, Banerjee Para Road, PO+PS, Nabadwip 741302, Nadia District, West Bengal, India. Mob: 9477119979/8372907265;

e-mail: raz.basu@gmail.com

Received 22 October 2017

Accepted 26 November 2017

The Egyptian Journal of Internal Medicine 2018, 30:43-46

\begin{abstract}
Superior vena cava (SVC) syndrome occurs because of SVC obstruction by mediastinal mass, with features of venous stasis and Pancoast syndrome manifested by tumour of the lung apex with features of invasion to adjacent bones, soft tissues and the nervous system. Small cell carcinoma lung is commonly found to cause SVC syndrome, Pancoast is a rare association. Only a few cases have been reported so far. In this report, we focus on a 45-year-old male patient who presented with both Pancoast and SVC syndrome because of small cell carcinoma of the lung.
\end{abstract}

\section{Keywords:}

Pancoast tumour, small cell carcinoma lung, superior vena cava syndrome, transbronchial biopsy

Egypt J Intern Med 30:43-46

(C) 2018 The Egyptian Journal of Internal Medicine

1110-7782

\section{Introduction}

Superior vena cava (SVC) syndrome is associated strongly with malignant tumours (right-sided lung cancer is more common) and mediastinal mass presenting with swelling of the face, neck and enlarged veins of the upper chest (features of SVC obstruction) [1].

Pancoast tumour is manifested by signs and symptoms because of secondary neoplastic invasion to the brachial plexus, adjacent vertebral bodies, the first two thoracic nerves, the cervical sympathetic chain and stellate ganglion, outer pleura for the position of tumour in the superior sulcus and the total set of signs and symptoms known as Pancoast syndrome. The clinical spectrum of the symptoms includes pain in the shoulder and ipsilateral affected arm and hypoaesthesia along the forearm, gradually leading to weakness and muscle atrophy of the ring finger and little finger. Stellate ganglion involvement is manifested as palpebral meiosis, enophthalmos, anhidrosis and ptosis, also known as Horner's syndrome, a subset of Pancoast [2].

Although small cell carcinoma lung is a common cause for SVC syndrome, in the histology of Pancoast syndrome, it is rare [3].

Here, we report a case of small cell carcinoma manifested by both Pancoast and SVC syndrome.

\section{The case}

A 45-year-old nonhypertensive nondiabetic male patient presented with the complaint of shortness of breath and cough for the last 2 months, progressively deteriorating, gradually associated with hoarseness of voice, and swelling of the face and upper extremities. In further evaluation of history, the patient also complained of difficulty in deglutition of solids.

His breathing problem was not aggravated or relieved with change in position and his cough was dry or sometimes with scanty sputum expectoration without hemoptysis. All of his symptoms were progressive in nature and associated with intermittent right shoulder pain radiating along the upper limb of that side and hand muscle weakness.

There was no history of fever, chest pain, headache, dimness of vision and palpitation.

The patient was a chronic smoker from adolescence and smoked 30 packs per year. There was no history of alcohol consumption and no relevant family history.

On examination, Glasgow Coma Scale was $\mathrm{E}_{4} \mathrm{~V}_{5} \mathrm{M}_{6}$, blood pressure was 122/74, pulse rate was $88 \mathrm{bpm}$, mild pallor was present, there was no cyanosis, clubbing or icterus, and no neck gland was palpable. Facial puffiness was present (Fig. 1). The neck veins were engorged and nonpulsatile. His teeth were stained black (probably because of heavy smoking).

This is an open access article distributed under the terms of the Creative Commons Attribution-NonCommercial-ShareAlike 3.0 License, which allows others to remix, tweak, and build upon the work noncommercially, as long as the author is credited and the new creations are licensed under the identical terms. 
There were visible venous prominences over the chest and the upper back. There was diminished vesicular breath sound on the upper zone of the right lung on chest auscultation and a dull note on percussion over the apical area. There was no paradoxical respiration.

There was swelling of both upper limbs and weakness of the medial half of the hand, but no atrophy. Both pupils were of normal size and reacted to light. No abnormalities were detected in other systemic examinations.

Routine blood examinations showed no significant findings, except erythrocyte sedimentation rate: 81, calcium (corrected): 10.2. Chest radiography posteroanterior view showed collapse of the right upper lobe with a 'Golden S sign' (Fig. 2). Computed tomography thorax showed a right upper lobe bronchogenic mass lesion with central degenerative changes (Fig. 3). Computed tomography-guided fine needle aspiration cytology and Tru-cut biopsy reports were inconclusive on two different occasions.

Bronchoscopy-guided biopsy was planned; bronchoscopy indicated widened carina and infiltrating growth in the

\section{Figure 1}

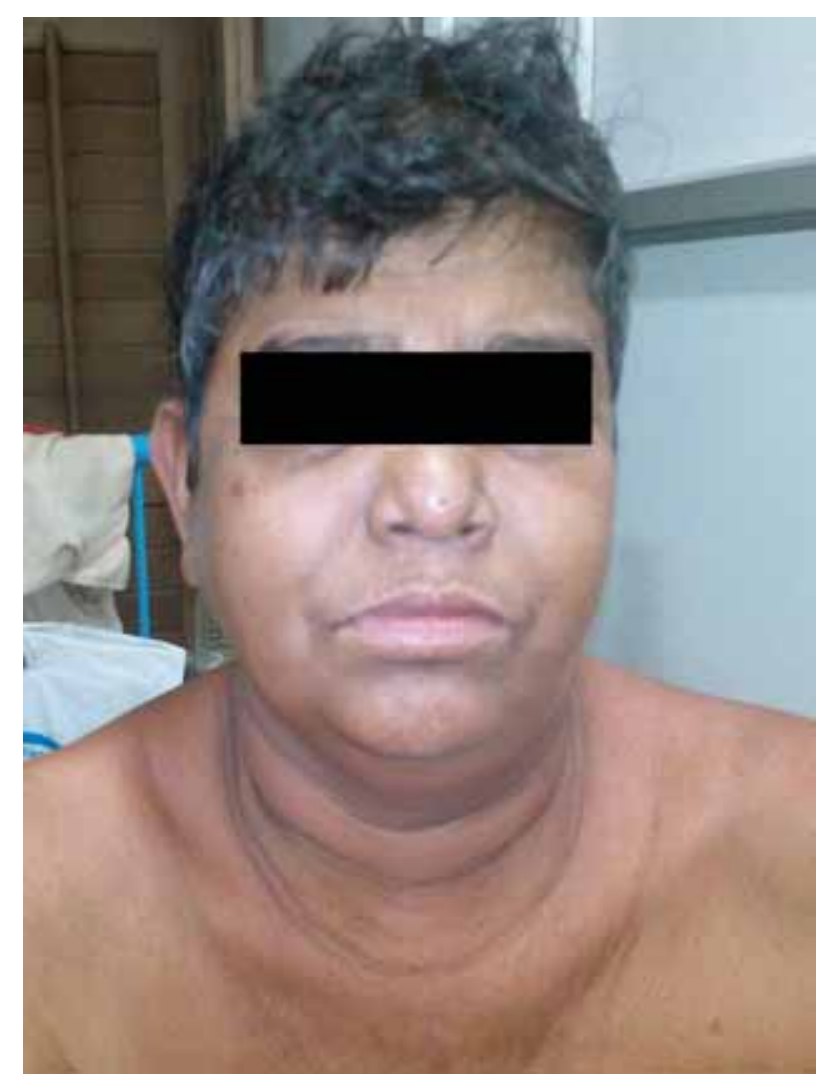

Facial puffiness due to SVC syndrome. wall of the right main bronchus. Histopathological examination showed a tumour composed of small, round, oval and spindle-shaped cells with hyper chromatic nuclei and scanty cytoplasm and mitotic figures, compatible with small cell carcinoma. The findings were confirmed with immunohistochemistry.

After the diagnosis was made, the patient was placed on carboplatin $600 \mathrm{mg}$ on day 1 and etoposide $160 \mathrm{mg}$ for consecutive 3 days in the first cycle. The patient was discharged to radiotherapy for further treatment.

\section{Discussion}

From the case history, the patient had Pancoast syndrome and features of SVC obstruction. However, there were no signs of Horner's syndrome; still, patients with Pancoast syndrome without features of Horner's syndrome have been reported [4]. The features of SVC obstruction are similar to small cell cancer of lung, evident from the literature [1].

Pancoast tumour is usually of a non-small cell variety on histology, adenocarcinoma being the most common [5]. The small cell variety of Pancoast tumour has rarely been reported in the literature [3,6-9]. The first four cases were reported by Johnson et al. [3]. Subsequently, Gupta and Malik [6], Mizoguchi et al. [7], Lands et al.

\section{Figure 2}

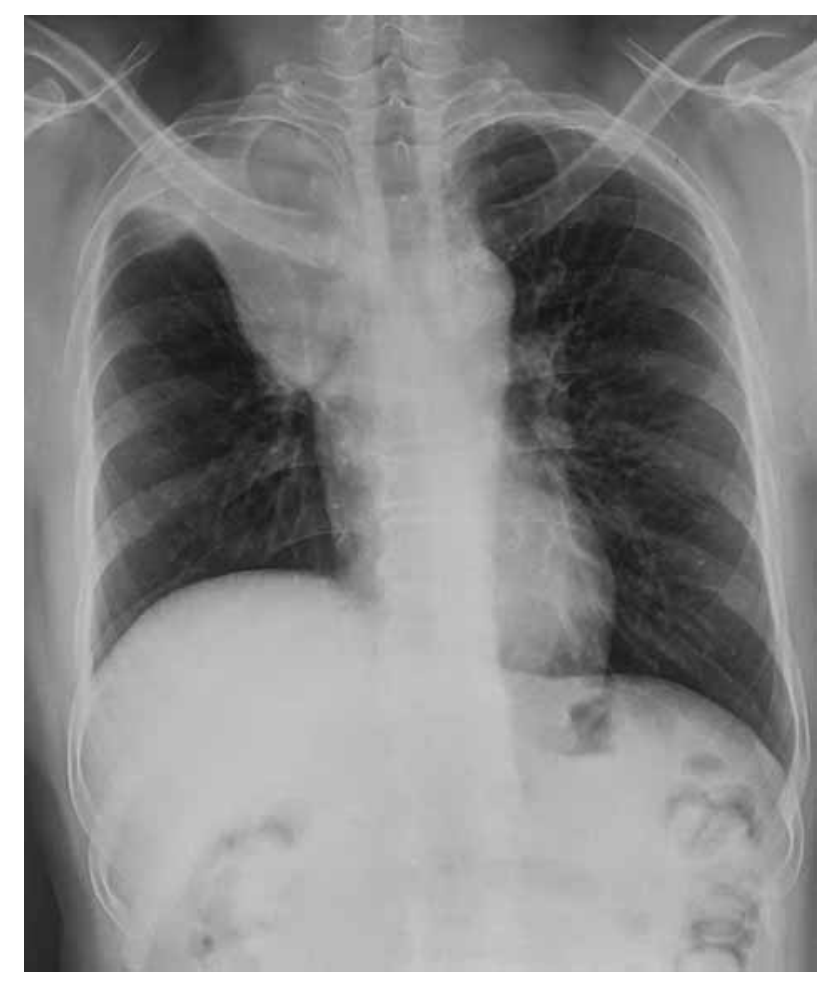

X-ray chest showing right upper lobe collapse and Golden S sign. 


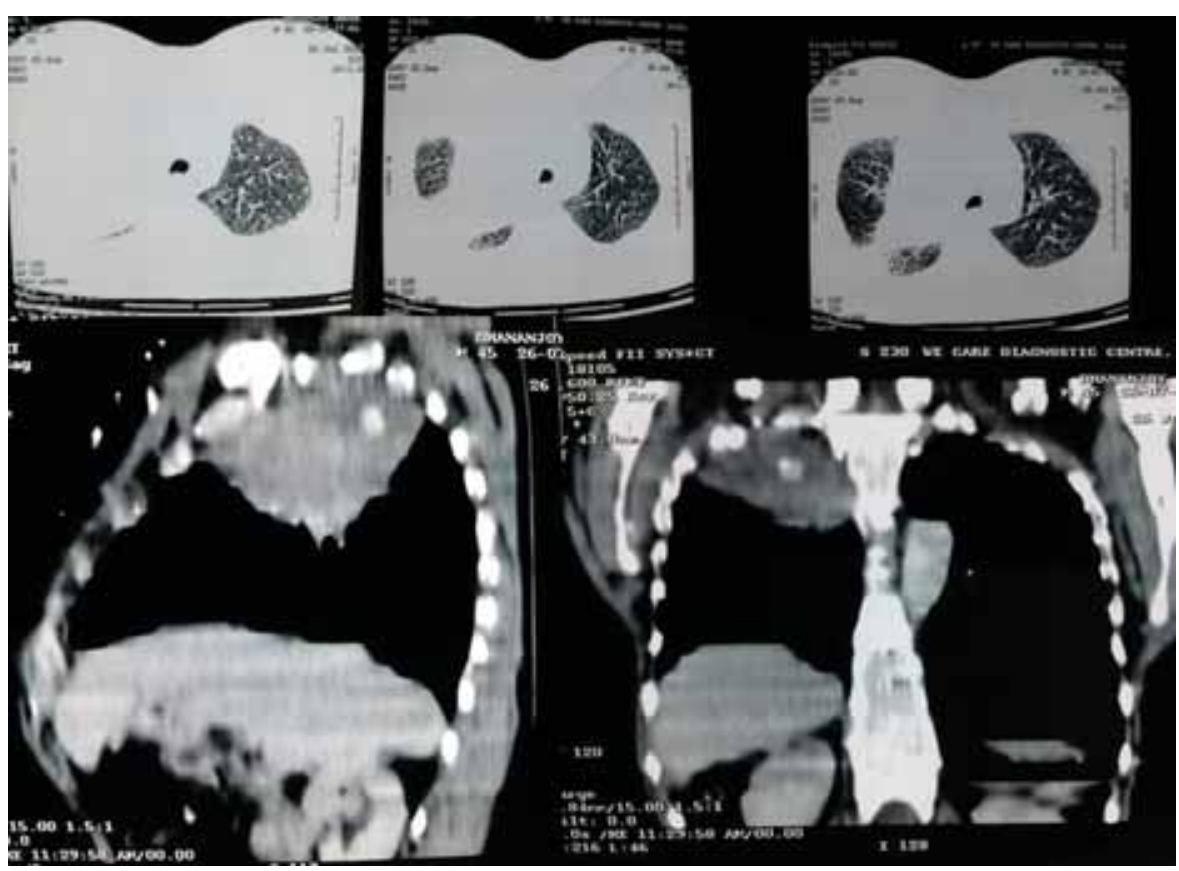

CECT thorax showing right upper lobe SOL with calcification.

[8] and Fontinele e Silva et al. [9] presented similar evidences in their studies.

In our case, the patient was diagnosed with small cell carcinoma in a bronchoscopic biopsy as transthoracic biopsies on various occasions did not help. Usually, bronchoscopic-guided biopsy has low diagnostic value because of the difficult position of the tumour in this scenario [9]. However, an earlier case had been diagnosed with bronchoscopy as can be found in the literature [10].

Immunohistochemistry was positive for cytokeratins, synaptophysin, neuron-specific enolase, chromogramin $A$ and CD56. These all are supportive of our diagnosis and recently diagnosed CD56 is most sensitive tool among them [11].

Chemotherapy is the standard mode of treatment of small cell carcinoma to be started early with or without radiation [9]. Here, we started with carboplatin and etoposide initially and discharged the patient for radiotherapy follow-up (as chemotherapeutic agents are not available in the medicine ward in our hospital). We are still monitoring the patient on an outpatient basis and he is happy with some improvements of his breathing problem.

\section{Conclusion}

We can say that Pancoast tumours are not necessarily of non small cell variety; on the basis of the increasing incidences of cases with small cell histology, it is evident that biopsy and confirmation of histological diagnosis are vital before deciding on a treatment.

\section{Declaration of patient consent}

The authors certify that they have obtained all appropriate patient consent forms. In the form the patient(s) has/have given his/her/their consent for his/her/their images and other clinical information to be reported in the journal. The patients understand that their names and initials will not be published and due efforts will be made to conceal their identity, but anonymity cannot be guaranteed.

\section{Financial support and sponsorship}

Nil.

\section{Conflicts of interest}

There are no conflicts of interest.

\section{References}

1 Brzezniak C, Oronsky B, Carter CA, Thilagar B, Caroen S, Zeman K. Superior vena cava syndrome in a patient with small-cell lung cancer: a case report. Case Rep Oncol 2017; 10:252-257.

2 Arcasoy SM, Jett JR. Superior pulmonary sulcus tumors and Pancoast's syndrome. N Engl J Med 1997; 337:1370-1376.

3 Johnson DH, Hainsworth JD, Greco FA. Pancoast's syndrome and small cell lung cancer. Chest 1982; 82:602-606.

4 Khosravi Shahi P. Pancoast's syndrome (superior pulmonary sulcus tumor): review of the literature. An Med Interna 2005; 22:194-196.

5 Archie VC, Thomas CR Jr. Superior sulcus tumors: a mini-review. Oncologist 2004; 9:550-555.

6 Gupta RC, Malik SK. Pancoast's syndrome and small cell lung cancer. Indian J Chest Dis Allied Sci 1983; 25:161. 
7 Mizoguchi K, Tsunekawa H, Niwa Y, Shimokata K. A case of Pancoast's syndrome induced by small cell carcinoma. Nihon Kyobu Shikkan Gakkai Zasshi 1984; 22:800-803.

8 Lands RH, Patel N, Maran S, Karnad A. Small cell lung cancer presenting as a Pancoast tumor. J Tenn Med Assoc 1991; 84:113-114.

9 Fontinele e Silva J, Barbosa Mde P, Viegas CL. Small cell carcinoma in Pancoast syndrome. J Bras Pneumol 2009; 35:190-193.
10 Echave-Sustaeta JM, Villena MV, López Encuentra A, de Miguel Poch E. Pancoast syndrome secondary to small-cell bronchogenic carcinoma. Diagnosis with transbronchial biopsy. An Med Interna 1994; 11:345-346

11 Kontogianni K, Nicholson AG, Butcher D, Sheppard MN. CD56: a useful tool for the diagnosis of small cell lung carcinomas on biopsies with extensive crush artefact. J Clin Pathol 2005; 58:978-980. 